\title{
DO BLOG AOS CONTOS: BIOGRAFEMAS POSSÍVEIS EM POSTS E NARRATIVAS DE MARCELINO FREIRE
}

\author{
FROM BLOG TO TALES: POSSIBLE BIOGRAPHEMAS IN MARCELINO FREIRE'S \\ POSTS AND NARRATIVES
}

\begin{abstract}
Alexandre José Ventura da Silva ${ }^{\mathrm{I}}$
RESUMO: A obra do escritor Marcelino Freire apresenta fragmentos (auto)biográficos que são ficcionalizados em contos e personagens. A proposta desta pesquisa é verificar como podemos associar tais fragmentos ao conceito de biografema, de Roland Barthes. Índices comprobatórios de realidades que se materializam em "vivos lampejos romanescos" no blog e nas narrativas de Freire.
\end{abstract}

Palavras-chave: Marcelino Freire. Biografema. Blog.

ABSTRACT: Marcelino Freire's literary work presents (auto)biographical fragments that are fictionalized in short stories and characters. The proposal of this research is to verify how we can associate such fragments with the concept of biographema, by Roland Barthes. Evidential indexes of realities that materialize in "alive romanescos flashes" in Freire's blog and narratives.

Keywords: Marcelino Freire. Biographema. Blog.

INTRODUÇÃO

Em entrevista sobre o lançamento de seu primeiro romance, Nossos Ossos, o escritor pernambucano Marcelino Freire é enfático ao afirmar que "qualquer semelhança com a minha história é, sim, autopornográfica" (Filholini; Andrade, 2014). Nossos Ossos conta a história de um dramaturgo de Sertânia que vive em São Paulo e volta ao Nordeste para entregar o corpo de um garoto de programa assassinado aos pais. $\mathrm{O}$ autor confronta-se nessa saga com suas próprias questões identitárias. "Peguei emprestado alguns aspectos autobiográficos, usei Sertânia, minha terra natal, como paisagem da história, usei as minhas impressões primeiras de São Paulo, [cidade] em que vivo" (Trigo, 2014), reafirma o escritor, traçando um tênue limite entre o real e o ficcional.

Já no conto "União Civil", do livro Amar é crime, Freire narra a história de um também escritor que participa de uma feira literária. O personagem é indagado sobre como descobriu que

${ }^{1}$ Mestrando do Programa de Pós-graduação em Ciências da Linguagem da Universidade do Sul de Santa Catarina (Unisul), Palhoça/SC, Brasil. 
queria ser escritor. "A impressão que eu tenho é que um conto nasce em algum ponto da vida da gente. Ele fica lá, congelado, esperando que algo o acorde, algo o provoque" (Freire, 2015, p.86), responde, em um embate entre memória e invenção.

Entre a ficção e a realidade, a memória e a invenção, Marcelino Freire se constitui em seu espaço biográfico. Em entrevistas, vídeos e palestras, o autor insinua detalhes de vida, do presente, do passado, que são perceptíveis em sua obra. A obra de Freire guarda, assim, traços, resquícios, fragmentos (auto)biográficos que são ficcionalizados em narrativas e personagens. $O$ espaço biográfico de Freire e a escrita (auto)ficcional permitem identificar biografemas norteadores. Índices comprobatórios de realidades que se materializam em "vivos lampejos romanescos", como afirma Roland Barthes para explicar o seu conceito de biografema.

Barthes assinala que o biografema não objetiva uma verdade absoluta: a narrativa dos fatos de uma vida não precisa, necessariamente, fazer conexão ou sentido; o que importa é a leitura, a recepção do texto pelo leitor - e não o que foi escrito pelo autor. Pormenores da vida de Marcelino Freire - relações familiares, ofício de escritor, amores, sexualidade, mudança para centro urbano - ganham, assim, uma nova vida em sua literatura.

A proposta desta pesquisa é verificar como o conceito de biografema pode ser associado à escrita de Marcelino Freire - seja em suas narrativas ou nos posts de seu blog Ossos do Ofídio.

I Barthes e o conceito de biografema

"Tudo isso deve ser considerado como dito por uma personagem de romance". Assim inicia- se, a partir da reprodução de uma frase manuscrita pelo autor Roland Barthes, a proposta de leitura da vida do personagem Roland Barthes. Em Roland Barthes por Roland Barthes, imagens e textos remetem a fragmentos de um Barthes que organiza e estrutura seu relato como uma biografia, mas não deixa de sugerir que tal relato pode ser um romance - e que o Barthes retratado é ficção. Um distanciamento de si, uma estratégia narrativa ou uma provocação ao leitor?

Barthes nos oferece uma narrativa telegrafada, poética, utilizando o fragmento como tática de escrita (auto)biográfica. O tom nem sempre é retrospectivo; e apesar do nome próprio na capa da obra, remetendo a um autor (Roland Barthes), outros Barthes coexistem como narradores- personagens: eu, tu, ele e RB. Quatro eus que constroem uma narrativa fragmentada, quatro vozes que, entre o factual e o ficcional, estão a serviço de um autor travestido de outros: "Quanto a mim, o 'eu' pode não ser o mim" (Barthes, 2003, p. 186).

Relato infiel de autores de si diversos, Barthes por Barthes é uma ficcionalização da vida do autor, com pessoas, lugares e situações reais. Um quebra-cabeça que se constrói lentamente, pelo prazer de quem o escreve (os vários Barthes) e de quem o lê (os vários leitores), com Barthes 
estabelecendo o conceito de biografema como regra principal dessa narrativa.

Publicado em 1975, Roland Barthes por Roland Barthes traz diversos critérios para, à primeira vista, o lermos enquanto autobiografia do autor: título em sua referência; nome próprio na capa; presença da figura do autor como personagem construído discursivamente. Mas o que torna, apesar de todos esses índices comprobatórios autobiográficos, a obra, na verdade, um romance autoficcional, um simulacro de autobiografia? O próprio Barthes já nos sinaliza que

embora feito, aparentemente, de uma sequência de ideias, este livro [...] é o livro do Eu, o livro de minhas resistências a minhas próprias ideias. [...] A substância deste livro, enfim, é, pois, totalmente romanesca. [...] que o ensaio confesse ser quase um romance: um romance sem nomes próprios

(BARTHES, 2003, p.136).

Barthes organiza as experiências dos seus sujeitos de si mesmo - "eu, tu, ele e RB” - por meio de fragmentos e anotações, propondo o conceito de biografema. Pelo biografema, uma (auto)biografia se relacionaria à ficção ao isolar traços dispersos da vida de um sujeito, pelo recorte de pormenores isolados, para compor uma biografia descontínua. Barthes sinaliza que a narrativa de uma vida não precisa apresentar-se sob a forma estrutural de uma autobiografia tradicional (princípio, meio e fim). Importa entender o biografema enquanto traço biográfico de um sujeito.

A utilização de biografemas em Barthes por Barthes seria, por consequência, um jogo com o leitor, uma provocação do texto. Barthes provoca o leitor, não entregando uma obra acabada, mas fragmentos, biografemas (auto)ficcionalizados que podem ser lidos aleatoriamente. Pelos fragmentos, os eus barthesianos guiam o leitor (ou o confundem?) para uma jornada introspectiva sem fingir, desde o início, que deve ser considerada como dita por uma personagem de romance. Assim, Barthes nos entrega uma antibiografia que, como o próprio sujeito que a escreve, colocase à margem de novas interpretações. Como biografemas que, aos fragmentos, compõem uma biografia descontínua dele. Ou de Marcelino Freire, como será tratado adiante.

I.I Biografemas possíveis em Marcelino Freire

Com oito livros publicados (sete de contos e um romance), além da participação em antologias no Brasil e no exterior, Marcelino Freire é um dos principais expoentes da literatura brasileira contemporânea. Nascido em Sertânia, no sertão de Pernambuco, filho caçula de uma família de nove irmãos, viveu no Recife da infância à juventude, onde fez teatro, frequentou oficina literárias e começou a escrever peças e contos. Da capital pernambucana mudou-se, em 199I, para a capital de São Paulo, influenciado "por um amor que tinha ido morar na cidade de pedra” (Guarda, 2014).

A narrativa de Freire é centrada no discurso direto, caracterizada por uma forte marca da 
oralidade. $\mathrm{O}$ estilo de prosa rápida e ritmada flerta com a poesia. $\mathrm{O}$ autor cita suas influências.

O que há de telegráfico no que eu faço vem da economia de Graciliano. [...] encontrei o meu caminho escrevendo, compactuando com a fala da minha mãe. Minha mãe me influenciou mais do que os grandes autores. A fala da minha mãe, a ladainha dela, as dores dela contaminaram, impregnaram a minha escrita. Uma escrita teatral, tragicômica (RAMOS, 2014).

Outro traço que marca a escrita do autor é o caráter autoficional que se apresenta em situações e personagens de suas obras. "Misturando realidade e ficção. Loucura e literatura. Memória e invenção. Meu Deus!” (Freire, 2015, p.8I). O narrador do conto “União civil”, tal como personificando o autor Marcelino Freire, conclui: "Os personagens me ensinaram a viver. A vida real. Depois de vários livros publicados, eu tinha mesmo que aprender" (Freire, 2015, p.85). Um aprendizado pelo qual o autor sequestra memórias, em vez de resgatá-las:

Quem resgata memória é historiador, sociólogo, arqueólogo. Escritor sequestra. Diz assim para a memória: e aí, vai confessar ou não vai? Pressiona, encosta contra a parede. [...] Vasculha, denuncia, desnuda. Entrega todo mundo. Sem piedade. A literatura violenta nossas lembranças, adentra fundo, cobra na fuça, sem delongas. [...] Quem escreve não quer saber de família. Eis que escancara a tia, o tio. Não respeita o pai. Renega a mãe. Os grandes livros pregam peça, jogam à merda o passado, o presente, o futuro. Repito: a literatura em vez de resgatar, sequestra. Põe a memória para recordar à força. [...] A memória é má. Moléstia. Escrever é rever. Mesmo sem querer olhar. Lembre-se sempre: a memória é feita daquilo que a gente não quer lembrar (FREIRE, 20I2b).

É em Nossos ossos, sobretudo, que Marcelino Freire vai (mais) além na fronteira entre realidade e autoficção em sua literatura. Todo o romance pode ser lido - e deduzido - pelos fragmentos biográficos que Freire sugere:

Éramos nove irmãos, ao todo, no sertão, a brincadeira era juntar ossos, de tudo que é animal [...], fazíamos teatro com as vértebras [...]. Minha dramaturgia veio daí, hoje eu entendo, desses falecimentos construí meus personagens errantes, desgraçados mas confiantes, touros brabos, povo que se põe ereto $e$ ressuscitado, uma galeria teimosa de almas que moram entre a graça e a desgraça. Escondi as carcaças e só juntei, outra vez, as duras armas quando recebi a terceira carta em que Carlos insistia, venha, sem você a vida é mais difícil, São Paulo te espera, um ano já faz que a gente se separou, o meu futuro mudou e o seu também vai mudar [...], experimentei, tentei ser ator, além de autor, também diretor, com toda a fé e entusiasmo, fazer do Recife o meu tablado, o meu sonho mambembe, para minha mãe falei, de repente, que havia chegado a minha vez de partir

(FREIRE, 2013, p.26).

Em Nossos Ossos, as trajetórias do escritor-sujeito Marcelino Freire e do escritorpersonagem Heleno de Gusmão se confundem: infância no sertão nordestino, ida para São Paulo, teatro, ofício de escritor, homossexualidade. "Eu estou neste livro de corpo e alma. [...] Sei onde meti minha 'costela' em cada uma das passagens e paisagens dessa saga gay" (Filholini; Andrade, 
2014), como afirma o autor. O protagonista Heleno transforma-se em um devir de um outro eu:

É um livro que vem mais com a minha voz. [...] Eu, na verdade, tive que me cercar de mim, até autobiograficamente, para não perder o romance. Para escrever o Nossos Ossos eu tive de montar um esqueleto mínimo para não perder a história. E esse esqueleto, sim, passa por mim, por minha voz, repito, por minha chegada a São Paulo, pelo Recife de minha adolescência, pelo teatro que fiz em Água Fria, pelos abandonos que sofri nessa trajetória toda, enfim. Posso dizer que apelei, eu apelei a mim para construir um outro eu, um quase alter-ego, digamos, que é o meu irmão do peito Heleno de Gusmão (RAMOS, 2014).

Como se percebe, o espaço biográfico de Marcelino Freite e a autoficção que se revela na escrita permitem identificar biografemas norteadores da obra do autor. Biografemas que se traduzem em narrativas: é pela recepção do leitor, pela leitura - aleatória, episódica, constante de contos e fragmentos, que Freire diz algo sobre si, formando uma imagem do autor.

O blog atualizado pelo autor entre 2011 e 2017 nos dá pistas de sua escrita permeada por biografemas. "Esse blog é muito mais meu do que dos outros, entende?" (Santos, 2013), provoca. Em Ossos do ofídio, Marcelino Freire publicava pequenos poemas, impressões e reminiscências, por vezes abrindo seu álbum de fotos de família.

A infância, por exemplo, surge em dois posts ilustrados com fotos. Em "Marcelinho", o reencontro de uma foto antiga torna-se o pormenor, o fragmento do biografema barthesiano que vai servir de mote para uma ficcionalização de sua vida: "Esta foto estava perdida de mim. Primeiro, foi encontrada no baú de minha avó. Depois hoje, aqui, nas coisas de casa. Ela, rerevelada. Possivelmente, a foto mais antiga minha, que eu tenho. Ou que eu voltei a ter. Voltei a ser” (Freire, 20IIc). Já no post "Doentinho", Freire recria, pela ficção, sua vocação às artes desde criança: "Foi novinho assim, com carinha de menininha, que descobri a poesia de Manuel Bandeira. Conto sempre, quando me perguntam sobre influências. A partir da poesia do Bandeira é que eu quis ser poeta. E tuberculoso" (FREIRE, 2orra).

Leonor Arfuch diz que "a infância será a ancoragem obrigatória de todo o devir, lugar sintomático cuja funcionalidade não tem a ver somente com uma coerência narrativa, mas também explicativa" (Arfuch, 2010, p.199). Para a autora, a amostragem de episódios da infância de um sujeito-autor, das relações familiares estabelecidas e de lembranças recorrentes acaba por tecer um romance familiar com efeitos de identificação junto aos leitores. Mais do que formar um romance familiar, para Sylvia Molloy (2003) as petites histoires (episódios triviais que a infância e o passado familiar oferecem) às quais o autor recorre para "conseguir ser em seu texto" (Molloy, 2003, p.13I) são ratificadas como começos necessários para se montar um relato de vida.

O ofício de ser escritor é outro biografema recorrente nas narrativas de Marcelino Freire. Para Arfuch, trata-se de um elemento notório encontrado na obra de um autor cujo trabalho é o "verdadeiro motor do devir humano" (Arfuch, 2010, p.20I). No post "Eu e Jean Genet", Freire 
mais uma vez ficcionaliza, por meio de um fragmento, o contentamento com sua carreira artística:

Meu nome batiza a sala de leitura do Aníbal Bruno [presídio no Recife]. Os próprios presos que escolheram. Teria de ser um nome de um autor pernambucano contemporâneo.

- Meu primo falou que o mais entusiasmado com você era um travesti, é, foi. Talvez por causa de alguns contos meus, gays, não sei. Senti-me Jean Genet. (FREIRE, 20Ib).

Dentre tantas possibilidades na vida de um sujeito, é pela vocação, iniciada ainda na infância, que ele triunfa:

Eu era uma figura que, em casa, fazia tudo o que meus sete irmãos não faziam, por exemplo, escrever as cartas da casa, porque eu já gostava de ler e escrever. [...] Não me mandassem fazer trabalho pesado! Meu trabalho era mais intelectual. Nesse sentido, eu era muito respeitado por esse ofício. [...] Eu até tenho em minha memória muita gratidão nesse sentido, porque foi a primeira vez que eu senti ser respeitado pelas escolhas que eu fiz. Eu era respeitado naquela função que eu desempenhava. Eu era respeitado como escritor, como leitor. (GRÜNNAGEL; WIESSER, 2015, p.446).

Como aponta Freire no excerto acima, a troca, na infância, de atividades mais introspectivas e intelectuais do que físicas, comumente associadas aos meninos, o diferenciava dos irmãos. Freire ficcionaliza a vocação na infância no conto "Balé”, em que um menino se dedica ao balé em vez de ajudar a família no trabalho braçal:

Disse que não, não vai cortar cana, morrer, moer neste sol. Disse que não, não vai ajudar o pai, salvar a mãe, os irmãos. [...] Disse que não sobe em caminhão. [...] Não quer sofrer no sufoco, não nasceu para mão-escrava. [...] Os irmãos saem para cortar mato e ele nem aí. [...] Vai seguir a sua vocação. Vocação? Agora mais essa, "vocação". [...] Sabe o que ele Fica fazendo enquanto a gente dá duro? Acredita que o negócio dele é ficar dançando? Vive atrás de vento, assobiando. Diz que segue canto de passarinho, que escuta água chover embaixo da terra. Vê só, ele ali na ponta quente da pedra se equilibrando

(FREIRE, 2003, p.33-35).

O tema da vocação às artes aparece, novamente, no conto "Amigo do rei", remetendo à influência de Manuel Bandeira na vida pessoal e profissional de Marcelino Freire, como já afirmado anteriormente. Vocação e relações familiares na infância são trazidos à tona nesse biografema transformado em narrativa; o menino prefere a poesia ao futebol, para desespero e incompreensão do pai, que vai buscar junto à escola uma resposta para a vocação artística do filho:

Bicha. É isso. Meu Deus! Gritou ele. Meu filho vai ser bicha. Credo! [...] Para que serve poesia? Quem colocou isso no seu juízo? Não acha bonito o futebol? [...] Foi à sala dos professores desabafar suas dores. Manuel Bandeira. Como é que é? A professora repetiu. Seu filho gosta do Manuel. [...] O pai amarelou. Ali mesmo desmaiou. Nem ouviu o final da

É um livro que vem mais com a minha voz. [...] Eu, na verdade, tive que me cercar de 
mim, até autobiograficamente, para não perder o romance. Para escrever o Nossos Ossos eu tive de montar um esqueleto mínimo para não perder a história. E esse esqueleto, sim, passa por mim, por minha voz, repito, por minha chegada a São Paulo, pelo Recife de minha adolescência, pelo teatro que fiz em Água Fria, pelos abandonos que sofri nessa trajetória toda, enfim. Posso dizer que apelei, eu apelei a mim para construir um outro eu, um quase alter-ego, digamos, que é o meu irmão do peito Heleno de Gusmão. (RAMOS, 2014).

Como se percebe, o espaço biográfico de Marcelino Freite e a autoficção que se revela na escrita permitem identificar biografemas norteadores da obra do autor. Biografemas que se traduzem em narrativas: é pela recepção do leitor, pela leitura - aleatória, episódica, constante de contos e fragmentos, que Freire diz algo sobre si, formando uma imagem do autor.

O blog atualizado pelo autor entre 2011 e 2017 nos dá pistas de sua escrita permeada por biografemas. "Esse blog é muito mais meu do que dos outros, entende?" (Santos, 2013), provoca. Em Ossos do ofídio, Marcelino Freire publicava pequenos poemas, impressões e reminiscências, por vezes abrindo seu álbum de fotos de família.

A infância, por exemplo, surge em dois posts ilustrados com fotos. Em "Marcelinho", o reencontro de uma foto antiga torna-se o pormenor, o fragmento do biografema barthesiano que vai servir de mote para uma ficcionalização de sua vida: "Esta foto estava perdida de mim. Primeiro, foi encontrada no baú de minha avó. Depois hoje, aqui, nas coisas de casa. Ela, rerevelada. Possivelmente, a foto mais antiga minha, que eu tenho. Ou que eu voltei a ter. Voltei a ser" (Freire, 20IIc). Já no post "Doentinho", Freire recria, pela ficção, sua vocação às artes desde criança: "Foi novinho assim, com carinha de menininha, que descobri a poesia de Manuel Bandeira. Conto sempre, quando me perguntam sobre influências. A partir da poesia do Bandeira é que eu quis ser poeta. E tuberculoso" (FREIRE, 20ira).

Leonor Arfuch diz que "a infância será a ancoragem obrigatória de todo o devir, lugar sintomático cuja funcionalidade não tem a ver somente com uma coerência narrativa, mas também explicativa" (Arfuch, 2010, p.199). Para a autora, a amostragem de episódios da infância de um sujeito-autor, das relações familiares estabelecidas e de lembranças recorrentes acaba por tecer um romance familiar com efeitos de identificação junto aos leitores. Mais do que formar um romance familiar, para Sylvia Molloy (2003) as petites histoires (episódios triviais que a infância e o passado familiar oferecem) às quais o autor recorre para "conseguir ser em seu texto" (Molloy, 2003, p.13I) são ratificadas como começos necessários para se montar um relato de vida. O ofício de ser escritor é outro biografema recorrente nas narrativas de Marcelino Freire. Para Arfuch, trata-se de um elemento notório encontrado na obra de um autor cujo trabalho é o "verdadeiro motor do devir humano" (Arfuch, 2010, p.20I). No post "Eu e Jean Genet", Freire mais uma vez ficcionaliza, por meio de um fragmento, o contentamento com sua carreira 
artística:

Meu nome batiza a sala de leitura do Aníbal Bruno [presídio no Recife]. Os próprios presos que escolheram. Teria de ser um nome de um autor pernambucano contemporâneo.

- Meu primo falou que o mais entusiasmado com você era um travesti, é, foi. Talvez por causa de alguns contos meus, gays, não sei. Senti-me Jean Genet

(FREIRE, 20IIb).

Dentre tantas possibilidades na vida de um sujeito, é pela vocação, iniciada ainda na infância, que ele triunfa:

Eu era uma figura que, em casa, fazia tudo o que meus sete irmãos não faziam, por exemplo, escrever as cartas da casa, porque eu já gostava de ler e escrever. [...] Não me mandassem fazer trabalho pesado! Meu trabalho era mais intelectual. Nesse sentido, eu era muito respeitado por esse ofício. [...] Eu até tenho em minha memória muita gratidão nesse sentido, porque foi a primeira vez que eu senti ser respeitado pelas escolhas que eu fiz. Eu era respeitado naquela função que eu desempenhava. Eu era respeitado como escritor, como leitor (GRÜNNAGEL; WIESSER, 2015, p.446).

Como aponta Freire no excerto acima, a troca, na infância, de atividades mais introspectivas e intelectuais do que físicas, comumente associadas aos meninos, o diferenciava dos irmãos. Freire ficcionaliza a vocação na infância no conto "Balé”, em que um menino se dedica ao balé em vez de ajudar a família no trabalho braçal:

\footnotetext{
Disse que não, não vai cortar cana, morrer, moer neste sol. Disse que não, não vai ajudar o pai, salvar a mãe, os irmãos. [...] Disse que não sobe em caminhão. [...] Não quer sofrer no sufoco, não nasceu para mão-escrava. [...] Os irmãos saem para cortar mato e ele nem aí. [...] Vai seguir a sua vocação. Vocação? Agora mais essa, "vocação". [...] Sabe o que ele Fica fazendo enquanto a gente dá duro? Acredita que o negócio dele é ficar dançando? Vive atrás de vento, assobiando. Diz que segue canto de passarinho, que escuta água chover embaixo da terra. Vê só, ele ali na ponta quente da pedra se equilibrando (FREIRE, 2003, p.33-35).
}

O tema da vocação às artes aparece, novamente, no conto "Amigo do rei", remetendo à influência de Manuel Bandeira na vida pessoal e profissional de Marcelino Freire, como já afirmado anteriormente. Vocação e relações familiares na infância são trazidos à tona nesse biografema transformado em narrativa; o menino prefere a poesia ao futebol, para desespero e incompreensão do pai, que vai buscar junto à escola uma resposta para a vocação artística do filho:

Bicha. É isso. Meu Deus! Gritou ele. Meu filho vai ser bicha. Credo! [...] Para que serve poesia? Quem colocou isso no seu juízo? Não acha bonito o futebol? [...] Foi à sala dos professores desabafar suas dores. Manuel Bandeira. Como 
é que é? A professora repetiu. Seu filho gosta do Manuel. [...] O pai amarelou. Ali mesmo desmaiou. Nem ouviu o final da história. Meu filho gosta de um outro menino. (FREIRE, 2014, p.94-97).

Ratificando a proposta de Arfuch da vocação como motor do devir humano, em post publicado na ocasião do aniversário de 47 anos, Freire refaz seu caminho, buscando entender o significado e a importância de festejar o novo ano de vida na França, onde foi lançar a tradução de Nossos Ossos:

Sei que foi o trabalho o que me trouxe aqui. As escolhas que eu fiz, a duras batalhas e penas, pelo caminho. O destino, em boa parte, nos guiando. Sem sair de Sertânia. Explico: estou aqui, como estive em outros cantos, mas quem me trouxe, sempiternamente, foram Sertânia, Paulo Afonso, Recife, São Paulo. As cidades também vão nos levando.Construindo, com a gente, a alma que finalmente carregamos (FREIRE, 2014b).

Os deslocamentos (geográficos e simbólicos) nas narrativas de Marcelino Freire também podem ser associados a biografemas. "Eu sou o escritor dos deslocamentos. Acho que tem a ver com a minha trajetória de imigrante" (Ramos, 2014), sugere Freire. Assim, a experiência de imigração sertão-cidade grande surge nos contos do autor e mais acentuada no romance Nossos Ossos. O dia da mudança definitiva para São Paulo é recordado por Freire em seu blog a partir da percepção do sentimento paterno:

A primeira vez em que vi meu pai chorar. Em que ele, na verdade, se engasgou. Ficou um vazio na voz. Porque meu pai foi um senhor duro. Embora bemhumorado. Um senhor de outro tempo. Sem abraços demorados. Nem derramamentos. [...] A hora em que peguei as malas. Soquei no automóvel. Dei a meia-volta para beijar os parentes. Todos ali, reunidos em minha despedida. Eu de partida decisiva para São Paulo. Caminhei em sua direção. Para agradecer por tudo o que ele me deu. Tudo o que eu estava levando comigo. Repito: aquela manhã de uma quinta-feira, dia II de julho do ano de 91. Meu pai, ali, diante de mim, não conseguiu dizer uma palavra. Apertoume a mão. Olhou nos meus olhos. Feito um amigo que nos olha. Com amor. Meu pai me amava. Todo em sua dor. Silenciosa. (FREIRE, 2012a).

Freire afirma que o deslocamento Recife-São Paulo foi determinante para o que há de urbano e caótico no que escreve. "O [livro] Angu de Sangue só foi possível quando vim morar em São Paulo. O angu da tradição, sertanejo, nordestino, em contato com a cidade de São Paulo virou um angu de sangue" (Freire, 2017). A mistura resultou na reafirmação de suas raízes:

São Paulo poluiu os meus parágrafos. Foi uma experiência traumática, essa de eu sair de minha terra e enfrentar uma cidade diferente, fria, grandiosa. Aqui, em São Paulo, tive que reafirmar as minhas origens. Todo mundo me perguntava de onde eu era e eu dizia: "de Sertânia". E isso foi uma afirmação importantíssima para mim. Reconhecer as minhas origens adormecidas. (RAMOS, 2014).

Esse reconhecimento de origem se reflete na saudade que o autor transparece em suas 
narrativas. "Rasif é um livro cheio de saudade. É um testamento, um inventário meu" (Santos, 2013), confirma o autor. Em "O futuro que me espera", um dos contos do livro, o personagem, por exemplo, após tantas lembranças faz o caminho inverso e retorna para a cidade natal:

Tenho saudades de Sertânia. [...] Saudades do amanhecer. Pra que pressa, pra quê?? Saudades [...] do trânsito de carros de boi. Da procissão que se foi. Maria vai com as outras. Saudades de tantas coisas. Que eu costurei a mala, levantei as paredes da caixa. Disse olhando os prédios de São Paulo. E a fumaça. Voume embora agora mesmo, de hoje não passa. Aqui nunca foi a minha terra. (FREIRE, 2014, p.I2I).

A temática dos deslocamentos em Marcelino Freire remete diretamente a outra questão: a sexualidade. Se a sexualidade se evidencia, inicialmente, no ambiente do sertão, é na metrópole urbana que ganha força, como pode ser observado no conto "Meus amigos coloridos":

Primeiro foi o Cadu. Não lembro. Kiko, o meu primo. Não lembro. Tudo no banho de ribeirão. A gente ia mergulhar no açude. Lodo de caramujo. [...] Depois apareceu o Hermes. [...] Hermes morava na Pompeia. Não podia ficar tarde. Eu tinha de pegar o metrô. Foi numa noite dessas que um assobio me convidou parta descer na Liberdade. Segui o assobio (FREIRE, 2005, p.91).

Em Nossos Ossos, o ambiente urbano de São Paulo vira um grande cenário para as investidas homossexuais do protagonista do romance, um escritor e dramaturgo migrante do sertão nordestino.

A primeira vez com um michê foi por engano, eu não entendi o que queria de mim o rapaz com cara de índio. [...] Aí ele me cobrou uma ajuda para o trem, para o lanche [...], eu dei e me acostumei a procurá-lo na Estação da Luz. FREIRE, 2013, p.33).

É nesse ambiente que mistura boates, botecos, gigolôs, michês, prostitutas e trabalhadores da noite que a temática da sexualidade é ficcionalizada por Freire, ancorada pelo conceito de metronormatividade. $\mathrm{O}$ termo ${ }^{\mathrm{T}}$ estabelece a cidade, o urbano como ambiente propício e referencial aos homossexuais (e demais "minorias de gênero") para vivenciar sua liberdade sexual; a migração de homossexuais para uma metrópole, de forma a ocupar locais comuns e promover uma formação identitária de sujeitos com mesmo gênero e/ou orientação sexual. Por esses deslocamentos simbólicos, o espaço urbano se transforma em habitat para incursões sexuais, legitimando determinadas áreas como gays - parques, cinemas, saunas, banheiros em que a liberdade se faz presente. Heleno de Gusmão, o personagem-narrador de Nossos Ossos, resume, em depoimento fictício ao escritor Paulo Lins na orelha do livro, como o conceito de metronormatividade reconfigura esse sujeito migratório por razões sexuais: "Nesta vida, amei os aplausos [...], o sexo de curiosidade com os artistas bem-sucedidos, as metidas de rua, adorei foder gostoso atrás do fliperama" (Freire, 2013). 
Considerações finais

Barthes apresenta o biografema como um traço biográfico de um sujeito, um pormenor que ganha [nova] vida na ficção. A partir de tais fragmentos, é construída uma imagem, como tal, fragmentada do sujeito pela recepção do leitor. "Vivos lampejos romanescos capazes de compor uma biografia descontínua", como define Barthes. E que, por analogia, são encontrados na obra de Marcelino Freire, como proposto nesta pesquisa.

É por biografemas como a infância, o ofício de escritor, os deslocamentos e a sexualidade nas narrativas freirianas que montamos um mosaico do autor. Nunca a imagem real, nem a representação; mas a recriação de um Marcelino Freire que se ficcionaliza em fragmentos e assim se oferece para os leitores:

Referências

Obras consultadas de Marcelino Freire

FREIRE, Marcelino. Amar é crime. Rio de Janeiro: Record, 2015.

. Angu de sangue. Cotia, SP: Ateliê Editorial, 2005.

. BaléRalé. Cotia, SP: Ateliê Editorial, 2003.

. Contos negreiros. Rio de Janeiro: Record, 2005.

. Nossos ossos. Rio de Janeiro: Record, 2013.

. Rassif: mar que arrebenta. Rio de Janeiro: Record, 2014.

Posts de blog de Marcelino Freire

FREIRE, Marcelino (2014b). 47 movimentos. São Paulo, 21 mar. 2014. Disponível em: https://marcelinofreire.wordpress.com/2014/03/21/47-movimentos/. Acesso em: 14 abr. 2018.

(2011a). Doentinhos. São Paulo, 28 abr. 20II. Disponível em: https://marcelinofreire.wordpress.com/2011/o4/28/doentinhos/. Acesso em: 14 abr. 2018.

(2011b). Eu e Jean Genet. São Paulo, I9 abr. 20Ir. Disponível em: https://marcelinofreire.wordpress.com/2011/o4/19/eu-e-jean-genet/. Acesso em: 14 abr. 2018.

(20IIc). Marcelinho. São Paulo, 2I dez. 20II. Disponível

em: https://marcelinofreire.wordpress.com/2011/12/21/marcelininho/. Acesso em: I4 abr. 2018.

(2012a). O dia em que meu pai chorou. São Paulo, I2 jul. 2012. Disponível em: https://marcelinofreire.wordpress.com/2012/o7/12/o-dia-em-que-meu-pai-chorou/. Acesso em: I4 abr. 2018.

(2012b). Sequestrar a memória. São Paulo, 9 mai. 2012. Disponível em: https://marcelinofreire.wordpress.com/2012/05/o9/sequestrar-a-memoria/. Acesso em: 14 abr. 2018.

Demais obras consultadas

ARFUCH, Leonor. O espaço biográfico - Dilemas da subjetividade contemporânea. Rio de Janeiro: EdUerj, 2 oro. 
BARTHES, Roland. Roland Barthes por Roland Barthes. São Paulo: Estação Liberdade, 2003.

FILHOLINI, Jorge; ANDRADE, Vinicius. A literatura que eu escolhi fazer tem me levado a lugares aonde eu nem imaginava estar. 2004. Disponível em:

$<$ https://livreopiniao.com/2014/04/17/marcelino-freire-a-literatura-que-eu-escolhi-fazer-jatem-me- levado-a-lugares-aonde-eu-nem-imaginava-estar/>. Acesso em: 29 jun. 2017.

FREIRE, Marcelino. "Eu escrevo para me vingar". São Paulo: TV Brasil, II ago. 2017. Entrevista ao programa de TV Estação Plural. Disponível em: 〈http://tvbrasil.ebc.com.br/estacaoplural/2017/o8/escritor-marcelino-freire-no-estacao-plural>. Acesso em: 14 fev. 2018.

GRÜNNAGEL, Christian; WIESER, Doris. "Sou um homossexual não praticante": Entrevista com Marcelino Freire. In: Estudos de Literatura Brasileira Contemporânea, Brasília, n. 45, p. 445462, jan./jun., 2015.

GUARDA, Adriana. Marcelino Freire foi para São Paulo no rastro de um amor (e ficou). Jornal do Commercio, Recife, 2014. Disponível em:

〈http://jconline.nero.uol.com.br/canal/suplementos/jc-mais/noticia/2014/II/o2/marcelinofreire- foi-para-sao-paulo-no-rastro-de-um-amor-e-ficou-154077.php>. Acesso em: 27 jun. 2017.

MOLLOY, Sylvia. Vale o escrito - A escrita autobiográfica na América Hispânica. Chapecó: Argos, 2003.

RAMOS, Thiago Corrêa. Entrevista - Marcelino Freire. 2014.

Disponível em: http://www.vacatussa.com/entrevista-marcelino-freire. Acesso em: 13 jan. 2018.

SANTOS, Márcio Renato. Algo em mim quer dar vexame. In: Cândido: Jornal da Biblioteca Pública do Paraná, Curitiba, n. 21, p. 4-9, abr. 2013.

TRIGO, Luciano. Marcelino Freire lança romance 'autopornográfico': "O lugar da minha escrita é o lugar do grito”. 2014. Disponível em: 〈http://gr.globo.com/pop-arte/blog/maquina-deescrever/post/marcelino-freire-lanca-romance-autopornografico-o-lugar-da-minha-escrita-e-olugar-do-grito.html>. Acesso em: 28 jun. 2017. 